\title{
33 BRINGING AN INTEGRAL APPROACH TO THE FIELD OF TECHNOLOGY DIFFUSION RESEARCH
}

\author{
Michael L. Ginn \\ Fielding Graduate University \\ Santa Barbara, CA, U.S.A.
}

\begin{abstract}
The intention in this position paper is to propose a possible new future for the technology diffusion research community, based on the integral approach of American philosopher Ken Wilber. The trends and current state of technology diffusion research are reviewed, and relevant aspects of Wilber's integral approach and its possible contributions are described. These aspects include Wilber's basic quadrants model and integral methodological pluralism, as well as the metapractices from which they arise.
\end{abstract}

Keywords Diffusion, integral, quadrants, Wilber

\section{A BRIEF HISTORY OF TECHNOLOGY DIFFUSION RESEARCH}

For much of the past 50 years, the field of technology diffusion has been dominated by a single theoretical leader: Everett Rogers. His 1962 classic, Diffusion of Innovations, is now in its fifth printing, and joins his 30 other books and some 500 articles. Useful models introduced by Rogers include the adopter curve, a five-stage process model of diffusion, elements of diffusion, the history of diffusion research, innovation roles, change agent characteristics, and the consequences of innovations. I have been greatly influenced by Rogers' models, extending his conception of innovator roles and their distinct concerns (Ginn 1994). Rogers' adopter curve, as adapted by Geoffrey Moore (2002), has introduced a generation of high-tech and marketing professionals to basic technology diffusion principles. Rogers has extended his diffusion principles to social issues such as family planning, drunk driving, and cancer prevention.

Please use the following format when citing this chapter:

Ginn, M. L., 2007, in IFIP International Federation for Information Processing, Volume 235, Organizational Dynamics of Technology-Based Innovation: Diversifying the Research Agenda, eds. McMaster, T., Wastell, D., Ferneley, E., and DeGross, J. (Boston: Springer), pp. 469-474. 
Over the past decade, however, diffusion research has diverged from this common ground. For instance, nearly half of the papers in the 1994 IFIP 8.6 proceedings cited Rogers, while only 4 out of 19 papers did so in 2006 . Similar developments in other research communities suggest that our field's decamping is a result of a broad historical movement rather than defects with or resolution of Rogers' theories. For example, the broader field of organizational science recently examined a similar theoretical divergence (Schoonhoven et al. 2005a, 2005b), and noted a mix of likely causes: a growing number of researchers, institutions, and consumers engaged in research; a growth in the number of acceptable epistemological stances and research methodologies; and an explosion of journals with varied viewpoints and requirements. Some suggested that this divergence could be best understood using a theory of paradigmatic change as introduced by Kuhn (1996) which explores an essential tension between tradition and novelty. However, I believe a more productive approach is a lens proposed by Tsoukas and Knudsen (2003). They reviewed how major historical movements in epistemology have impacted organizational theorists and their methodologies, building toward a framework which includes and relates research done from fundamentally different perspectives.

I propose that we adopt a similar, but a richer and more general approach to our research divergence: the integral theory of American philosopher Ken Wilber. This would not replace Rogers' seminal work, but rather include the important but partial truths of it and the divergences that have and will continue to take place.

\section{HOW AN INTEGRAL APPROACH COULD BE USEFUL TO TECHNOLOGY DIFFUSION RESEARCH}

What might Wilber's integral approach offer to our technology diffusion research community?

First, it may address the divergence of our research more powerfully that can crossdisciplinary, multiple methods, and other approaches we currently use. It might provide a more satisfactory theoretical framework from which to describe and work with the state of and trends of our technology diffusion research. It could also offer our research community a core set of social practices and methodologies that would powerfully relate our diverse elements and at the same time validate each of the methodologies currently in use. Finally, this integral approach offers the possibility of more powerful research with broader impact.

\section{QUADRANTS: A BASIC INTEGRAL MODEL}

Integral can be defined as comprehensive, balanced, inclusive, and essential for completeness. Wilber has refined this basic idea over the past several decades in some 30 books, including Sex, Ecology, and Spirituality (2001). A key model in his integral approach is the quadrants, as shown in Figure 1. It is a simple $2 \times 2$ matrix of singular/ plural and interior/exterior pairs.

The resulting intentional, behavioral, cultural, and social perspectives are not new inventions, but rather fundamental aspects of human experience. For example, most 


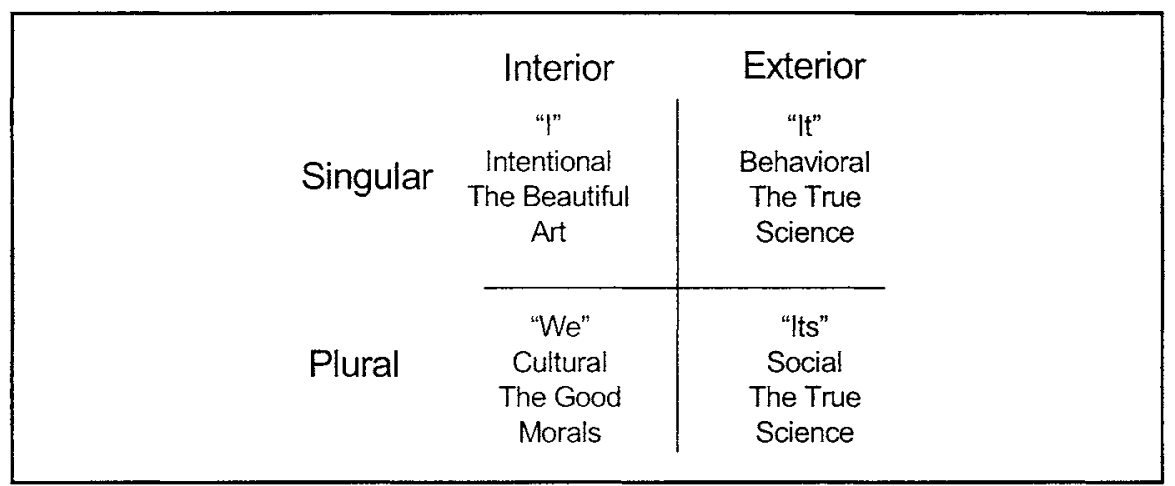

\section{Figure 1. Wilber's Basic Quadrants}

human languages have first-, second-, and third-person pronouns such as I, you/we, and it. Socrates recognized these three dimensions of our language-given reality as the Beautiful, the Good, and the True. Later, Max Weber and others would distinguish the cultural value spheres of art or the aesthetic expression of "I," the morals of "we," and the objective "its" of science. Habermas has in a similar way pointed to subjective, intersubjective, and objective domains.

It is useful to think of the quadrants as aspects of ourselves or perspectives though which we see the world, rather than as containers in which to put things.

\section{INTEGRAL METHODOLOGICAL PLURALISM}

Adding a bit of complexity to this basic idea of four quadrants is the idea that a perspective given by each quadrant can be further distinguished by objective or subjective approaches. For example, a subjective approach to interior, singular phenomena results in epistemologies and research practices like phenomenology, whereas an objective approach would result in structuralist approaches such as developmental psychology.

The primary defining characteristic of integral methodological pluralism (IMP) is acknowledging the importance and validity of each set of practices and methodologies that are in use: each has some important if partial truth. IMP can be seen as what will help establish a multipurpose toolkit that will enhance a tradition's chances of making a striking contribution to knowledge or to the conduct of industry or government. Alternatively, IMP can be seen as contributing to a mutual regard in which a richer diversity of interpretations can be held as a whole. IMP can also be seen as a framework that will embrace these enduring practices and methodologies yet transcend their partialisms, absolutisms, and exclusionary practices.

\section{IMPLICATIONS FOR PRACTICE}

Wilber, in his Excerpt B, describes how an integral methodological pluralism has two main parts. There is a paradigmatic aspect that is the result of a careful compilation of 


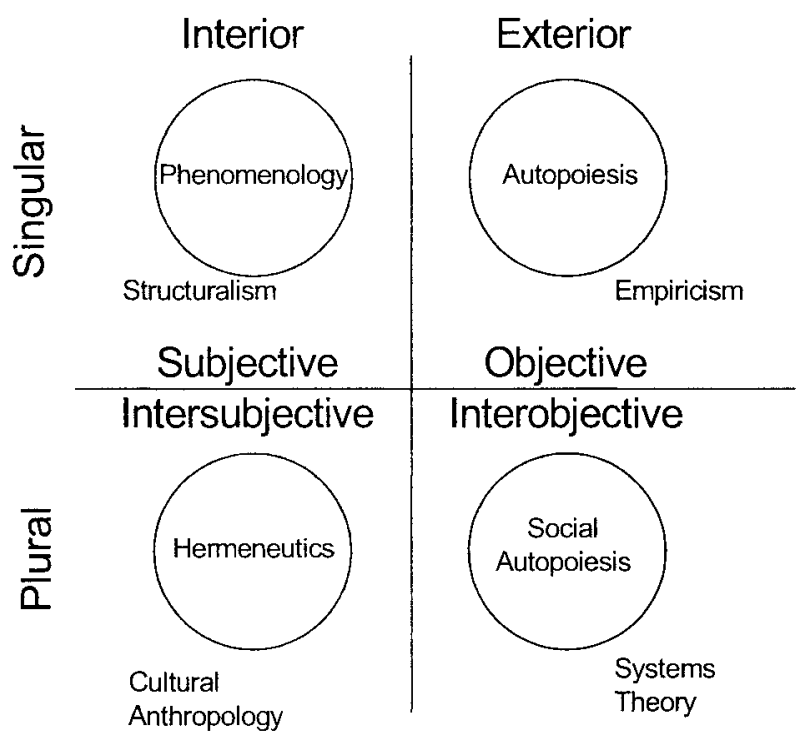

Figure 2. Eight Major Paradigms or Methodologies (Wilber, Excerpt D)

the accepted methods of a research community. These could be mapped using the IMP extension of the basic quadrants model as shown in Figure 2. This compilation would show major methodologies which currently enact, illume, bring forth the various world spaces and ways of being.

The second main part is a meta-paradigmatic set of practices that relate the various paradigmatic strands to each other. A new set of practices and methodologies weave these strands into "radically nonexclusionary ways of being-in-the-world." This follows from one of the basic heuristics of Wilber's integral approach, that "everyone is right" or holds an important if partial truth.

What practices can build bridges between other practices? While many will be uniquely developed by researchers in their various traditions, Wilber (Excerpt B) offers simultracking as one example. Phenomena of various domains are simultaneously tracked according to the accepted methodologies of those domains. The second main part of IMP, the meta-paradigmatic aspect, requires that the different methodologies address the same phenomena in such a way that correlations can be noted and also so that practices can be engaged to bring forth previously unrealized interrelationships between the world views enacted by their respective methodologies.

In addition to these social practices and methodologies, individual practices are critical to developing the capacity to be integrally informed. For example, an integrally informed researcher will be able to distinguish transdisciplinary studies, which "enact a new territory of integral displays between old rivals" (Wilber, Excerpt B), from crossdisciplinary ones, which simply confirm each other's prejudices. Another capacity would be to bring forth a radically nonexclusionary way of being-in-the-world. This involves 
more than accomplishing an intellectual understanding, adopting a belief, or taking a certain position such as pluralism for its own sake.

Integral methodological pluralism ultimately makes central the development of the researcher. This development is broad based, involving not just cognitive development, but also emotional, social, somatic, spiritual, and integrative development as well. It holds the intention and promise of higher development as suggested by, for example, Kegan (1986). It suggests a facility with human types such as gender differences and the Enneagram typology. It is grounded in a personal experience of various states of experience or consciousness and an adequate conception of how these are related to more general development.

One generic example of such a development approach is Wilber's (2006) integral life practice, which simultaneously engages and exercises a full range of human potentials and perspectives such as those suggested by his quadrants model. Another way to explain the scope of an integral life practice is to say that it both addresses the shortcomings and celebrates the advances of the modern world that most of us grew up in and still inhabit. It will work on resolving how, in us, arts and morals have been colonized by science. It will work on the disassociation of feeling from reason. It will celebrate and further develop empirical science's challenges to premodern myths.

\section{SUMMARY}

Wilber's integral approach and IMP present us with an opportunity to observe ourselves as a research community in a process of adoption, and then, as we master it, in a process of diffusion to other research communities. Ultimately these complex streams of discourse, centered on methodology, will become generalized and streamlined and enter the culture at large. This is an opportunity for us to be engaged in a historic forming of a broad societal shift in consciousness.

\section{References}

Ginn, M. L. "The Transitionist as Expert Consultant: A Case Study of the Installation of a RealTime Scheduling System in an Aerospace Factory," in L. Levine (ed.), Diffusion, Transfer and Implementation of Information Technology, Amsterdam: North Holland, 1994, pp. 179-198.

Kegan, R. The Evolving Self: Problem and Process in Human Development, Boston: Harvard University Press, 1986.

Kuhn, T. The Structure of Scientific Revolutions ( $3^{\text {rd }}$ ed.), Chicago: University of Chicago Press:, 1996.

Moore, G. Crossing the Chasm (Revised ed.), New York: HarperCollins, 2002.

Rogers, E. Diffusion of Innovations ( $5^{\text {th }}$ ed.), New York: Free Press, 2003.

Schoonhoven, C. B., Meyer, A. D., and Walsh, J. P. "Moving Beyond the Frontiers of Organization Science," Organization Science (16:5), 2005a, pp. 453-455.

Schoonhoven, C. B., Meyer, A. D., and Walsh, J. P. "Pushing Back the Frontiers of Organization Science," Organization Science (16:4), 2005b, pp. 327-331.

Tsoukas, H., and Knudsen, C. (eds.). The Oxford Handbook of Organization Theory: MetaTheoretical Perspectives, New York: Oxford University Press, 2003. 
Wilber, K. "Excerpt B: The Many Ways We Touch: Three Principles Helpful for Any Integral Approach," (available online at http://wilber.shambhala.com/html/books/kosmos/excerptB/ part1.cfm).

Wilber, K. "Excerpt D: The Look of a Feeling: The Importance of Post/Structuralism," (available online at http://wilber.shambhala.com/html/books/kosmos/excerptD/partl _cfm).

Wilber, K. Sex, Ecology, and Spirituality: The Spirit of Evolution $\left(2^{\text {nd }}\right.$ ed.), Boston: Shambhala Publications, 2001.

Wilber, K. Integral Life Practice Kit Starter Kit: The Simplest Practice You Can Do To Wake Up, Boston: Shambhala Publications, 2006.

\section{About the Author}

Mike Ginn lives in Carmel, California, with his wife Carol. He has worked at the Software Engineering Institute and Sun Microsystems. He is currently a doctoral student in Human and Organizational Systems at Fielding Graduate University where his research interests are driven by the integral approach of Ken Wilber. Mike can be reached by e-mail at mikeginn@, bethechange.com. 